\title{
Insights into the Catalytic Performance of Mesoporous H-ZSM-5-Supported Cobalt in Fischer-Tropsch Synthesis
}

\author{
Sina Sartipi, ${ }^{*}$ Margje Alberts, Vera P. Santos, Maxim Nasalevich, Jorge Gascon, ${ }^{*}$ and \\ Freek Kapteijn ${ }^{[a]}$
}

\begin{abstract}
Mesoporous H-ZSM-5 (mesoH-ZSM-5) was used as a carrier for a series of bifunctional Co-based catalysts for Fischer-Tropsch synthesis with $\mathrm{ZrO}_{2}$ and/or $\mathrm{Ru}$ added as promoters. The reducibility of the catalysts was studied in detail by using temperature-programmed reduction and X-ray absorption spectroscopy. A comparison of the catalytic performance of $\mathrm{Co} / \mathrm{mesoH}$ ZSM-5 and $\mathrm{Co} / \mathrm{SiO}_{2}$ (a conventional catalyst), after $140 \mathrm{~h}$ on stream, reveals that the former is two times more active and three times more selective to the $\mathrm{C} 5-\mathrm{C} 11$ fraction with a large content of unsaturated hydrocarbons, which is next to $\alpha$-olefins. The acid-catalyzed conversion of $n$-hexane and 1-hexene,
\end{abstract}

as model reactions, demonstrates that the improvement in the selectivity toward gasoline range hydrocarbons is due to the acid-catalyzed reactions of the Fischer-Tropsch $\alpha$-olefins over the acidic zeolite. The formation of methane over the zeolitesupported Co catalysts originates from direct CO hydrogenation and hydrocarbon hydrogenolysis on coordinatively unsaturated Co sites, which are stabilized as a consequence of a strong metal-zeolite interaction. Although the addition of either $\mathrm{ZrO}_{2}$ or $\mathrm{Ru}$ increases the catalyst reducibility considerably, it does not affect the product selectivity significantly.

\section{Introduction}

Fischer-Tropsch synthesis (FTS) is one of the most important achievements of chemical industry in the 20th century. The depletion of fossil resources over the last few decades, the increasing price of crude oil, the rapid increase in methane reserves, and environmental concerns have generated a worldwide interest in practical applications of FTS-based technologies. Different types of fossil- (natural gas and coal) and renewable-based feedstocks can be converted into industrially relevant chemicals, such as lower olefins and alcohols as well as ultraclean fuels, through the FTS reaction. ${ }^{[1]}$ The latter case is already commercialized through the so-called low-temperature Fischer-Tropsch (LTFT; catalyzed by Co or Fe) and hightemperature Fischer-Tropsch (HTFT; catalyzed by Fe) processes. ${ }^{[2]}$ However, these technologies are economically feasible only at large scales ${ }^{[3]}$ and therefore process intensification is needed in applications with limited (and scattered) availability of feedstock (e.g., biomass) and/or space (e.g., offshore flare gas).

Both LTFT and HTFT reactors are followed by product upgrading units in which hydrocracking and/or isomerization of the products of FTS are performed. ${ }^{[4]}$ Therefore, one way to

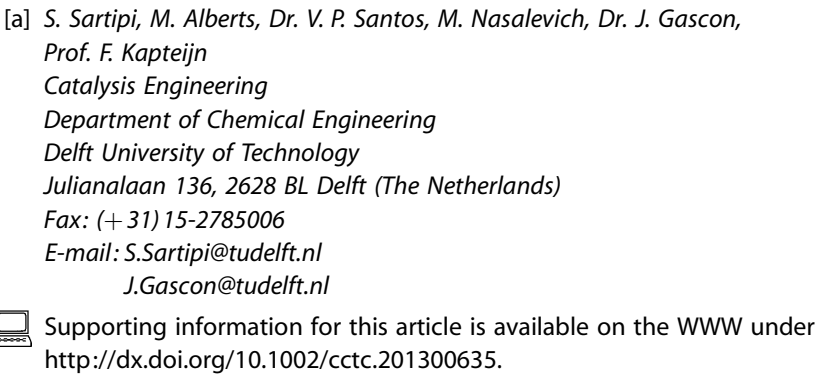

attain the above-mentioned process intensification is to tune the FTS product selectivity to eliminate the demand for downstream conversion units. ${ }^{[5]}$

Such efforts date to 1980s when combinations of zeolites with the FTS active phase were reported to "break" the classical Anderson-Schulz-Flory (ASF) product distribution. ${ }^{[6]}$ Since then, the integration of both Co- and Fe-based catalysts with various zeolite topologies has been studied at different levels, such as catalyst bed layers, ${ }^{[7]}$ physical mixtures of catalyst particles, $^{[8]}$ and coated catalysts. ${ }^{[9]}$ A 7.5 wt \% Co- 0.2 wt \% Ru catalyst supported on alumina-bound ZSM-5 has been reported recently to demonstrate a stable performance and high selectivity toward C5-C20 up to $1500 \mathrm{~h}$ on stream. ${ }^{[10]} \mathrm{Co}$ is claimed to be present mainly on the alumina binder of this hybrid catalyst.

A systematic comparison of different Co-zeolite catalyst configurations reveals that the selectivity toward liquid hydrocarbons increases as the proximity between FTS and acid sites increases in these hybrid systems. ${ }^{[11]}$ Such a contact can be maximized by directly dispersing Co over the zeolite. Because high metal loadings are typically required in the catalyst formulations for FTS and zeolites lack a sufficient external surface area, the use of mesoporous zeolites as catalyst carriers gave promising results. ${ }^{[12]}$ On the one hand, the improved transport properties of hierarchically structured zeolites increase the selectivity toward liquid hydrocarbons; ${ }^{[13]}$ on the other hand, their high mesopore surface area improves dispersion at elevated metal loadings. ${ }^{[11,13-14]}$ Insights into the catalytic performance of these bifunctional catalysts would enable us to fine-tune their product selectivity, which makes these catalysts attractive for practical applications. 
In an earlier work, we demonstrated that in an attempt to maximize the performance of bifunctional catalysts by steering the product selectivity toward liquid hydrocarbons, the topology of the zeolite and, most importantly, the number and strength of acid sites are key parameters. ${ }^{[14]}$ Herein, mesoporous H-ZSM-5-supported Co ( $\approx 20 \mathrm{wt} \%$ ) catalysts are studied further. Special attention is given to thoroughly characterize metal reducibility and to its improvement upon promoter addition. Hydrocarbon conversion mechanisms over acid sites and $\mathrm{Co}$ are investigated by using the conversion of $\mathrm{C} 6$ as a model reaction. The effect of such reactions on the product selectivity and origins of methane formation over the zeolitecontaining Co catalyst is discussed in detail. In all, through an advanced catalyst characterization along with a detailed catalyst assessment, a clear relationship is established between Co structural characteristics (if supported on the zeolite) and activity and selectivity in FTS.

\section{Results and Discussion}

\section{Catalyst characterization}

The total and mesopore surface area of H-ZSM-5 increases by 40 and $720 \%$, respectively, and its Si/Al ratio decreases from 41 to 22 after desilication with tetrapropylammonium hydroxide (TPAOH) owing to the creation of mesopores ${ }^{[15]}$ (Table 1).

\begin{tabular}{|c|c|c|c|c|c|c|c|}
\hline Support & $\begin{array}{l}\text { Treatment } \\
\text { sequence }\end{array}$ & $\begin{array}{l}S\left[\mathrm{~m}^{2} \mathrm{~g}^{-}\right. \\
\text {Total }^{[\mathrm{b}]}\end{array}$ & $\left.{ }^{1}\right]$ & $\begin{array}{l}V\left[\mathrm{~cm}^{3} \mathrm{~g}\right. \\
\text { Total }^{[\mathrm{d}]}\end{array}$ & Micro $^{[\mathrm{e}]}$ & Meso $^{[f]}$ & $\begin{array}{l}\mathrm{Si} / \\
\mathrm{Al}^{[\mathrm{a}]}\end{array}$ \\
\hline $\mathrm{SiO}_{2}$ & none & 290 & 250 & 1.35 & 0.02 & 1.34 & n.a. \\
\hline H-ZSM-5 & none & 460 & 50 & 0.26 & 0.18 & 0.08 & 41 \\
\hline mesoH-ZSM-5(o) & TPAOH & 650 & 430 & 0.68 & 0.10 & 0.58 & 22 \\
\hline mesoH-ZSM-5 & $\mathrm{TPAOH} / \mathrm{HNO}_{3}$ & 690 & 470 & 0.67 & 0.09 & 0.58 & 41 \\
\hline $\mathrm{ZrO}_{2} /$ mesoH-ZSM-5 & $\begin{array}{l}\mathrm{TPAOH} / \mathrm{HNO}_{3} / \\
\text { impregnation }\end{array}$ & 600 & 410 & 0.57 & 0.08 & 0.48 & n.d. \\
\hline
\end{tabular}

[a] Obtained from ICP-OES; [b] BET surface area; [c] Mesopore surface area obtained by using the $t$-plot method applied to the $\mathrm{N}_{2}$ isotherm; [d] Total pore volume; [e] Micropore volume obtained by using the $t$-plot method; [f] Mesopore volume calculated as $V_{\text {meso }}=V_{\text {total }}-V_{\text {micro }}$.

Moreover, the mesopore volume of mesoH-ZSM-5(o) is approximately 7 times larger than that of $\mathrm{H}-\mathrm{ZSM}-5$. This increase is at the cost of a slight decrease in micropore volume $(0.18$ and $0.10 \mathrm{~cm}^{3} \mathrm{~g}^{-1}$ for $\mathrm{H}-\mathrm{ZSM}-5$ and mesoH-ZSM-5(o), respectively), which indicates a minor collapse of the zeolite structure under basic conditions. ${ }^{[16]}$ Nevertheless, the XRD patterns of the corresponding catalysts (Figure $\mathrm{S} 1$ ) confirm that the characteristic MFI structure is preserved after desilication. ${ }^{[17]}$ The surface area and pore volume of mesoH-ZSM-5 are barely altered with respect to those of mesoH-ZSM-5(o); however, the zeolite Si/Al ratio is readjusted to the original value (41) after acid treatment (Table 1). It was shown earlier that (the used) treatment with $1 \mathrm{M} \mathrm{HNO}_{3}$ is effective only in removing the extra-frame-

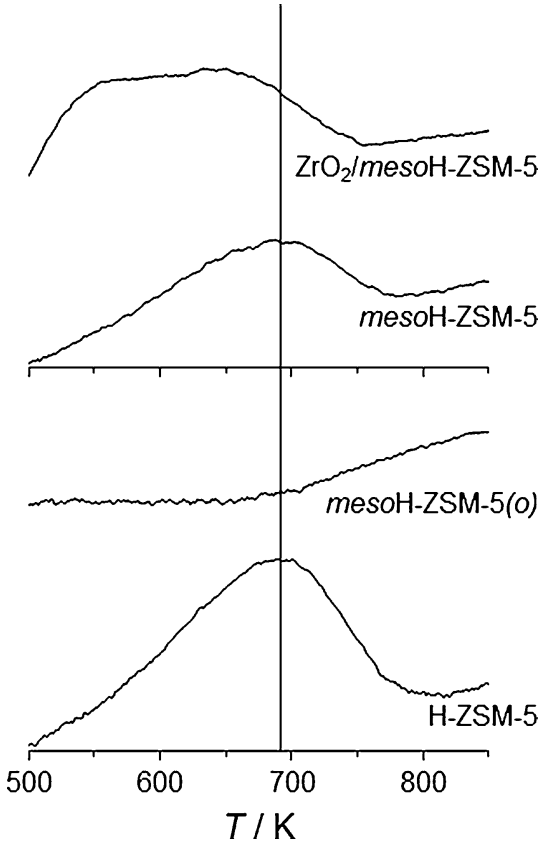

Figure 1. $\mathrm{NH}_{3}$-TPD profiles $\left(10 \mathrm{Kmin}^{-1}\right)$ of $\mathrm{H}-\mathrm{ZSM}-5$ zeolites. $\mathrm{NH}_{3}$ was adsorbed at $473 \mathrm{~K}$.

work aluminum species and does not leach out aluminum from the H-ZSM-5 framework. ${ }^{[13 b]}$

The temperature-programmed desorption of ammonia ( $\mathrm{NH}_{3}$-TPD) profile of $\mathrm{H}-\mathrm{ZSM}-5$ shows the characteristic peak of strong Brønsted acidity ${ }^{[12 a]}$ at approximately $700 \mathrm{~K}$ (Figure 1). This "high-temperature" peak is initiated by a tail at lower temperatures, which originates from weaker Lewis acid sites. ${ }^{[13 b]}$ Although mesoH-ZSM-5(o) does not show any desorption of $\mathrm{NH}_{3}$, mesoH-ZSM-5 shows a profile similar to that of H-ZSM-5 (notably, the peak at temperatures above $800 \mathrm{~K}$ corresponds to framework collapse, not to strong acidity).$^{[14]}$ We conclude that the initial treatment with TPAOH results in the partial ion exchange of the framework protons, which are recovered after acid treatment and calcination. The quantification of acidity through pyridine adsorption (Table 2) shows that the Brønsted acid density of
Table 2. Acid-type densities of H-ZSM-5 zeolites obtained through pyridine adsorption.

\begin{tabular}{|c|c|c|c|c|}
\hline \multirow[t]{2}{*}{ Support } & \multicolumn{2}{|c|}{ Brønsted acid } & \multicolumn{2}{|c|}{ Lewis acid } \\
\hline & {$\left[\mu \mathrm{molg}^{-1}\right]$} & {$\left[\mu \mathrm{mol} \mu \mathrm{mol}_{\mathrm{Al}}^{-1}\right]$} & {$\left[\mu \mathrm{molg}^{-1}\right]$} & {$\left[\mu \mathrm{mol} \mu \mathrm{mol}_{\mathrm{Al}}^{-1}\right]$} \\
\hline H-ZSM-5 & 138 & 0.35 & 37 & 0.09 \\
\hline mesoH-ZSM-5 & 74 & 0.18 & 38 & 0.09 \\
\hline
\end{tabular}

mesoH-ZSM-5 is lower than that of H-ZSM-5; nevertheless, the concentrations of Lewis acid sites are equal for both samples. The addition of $\mathrm{ZrO}_{2}$ slightly modifies the acidic properties of supports: the high-temperature peak shifts slightly to lower temperatures in the $\mathrm{NH}_{3}$-TPD profile of $\mathrm{ZrO}_{2} /$ mesoH-ZSM-5 
Table 3. Textural and chemical properties of the catalysts for FTS.

\begin{tabular}{|c|c|c|c|c|c|c|c|c|c|}
\hline \multirow[t]{2}{*}{ Catalyst } & \multicolumn{2}{|c|}{$S\left[\mathrm{~m}^{2} \mathrm{~g}^{-1}\right]$} & \multicolumn{3}{|c|}{$V\left[\mathrm{~cm}^{3} \mathrm{~g}^{-1}\right]$} & \multirow{2}{*}{$\begin{array}{l}d_{\mathrm{Co}{ }^{[\mathrm{a}]}} \\
{[\mathrm{nm}]}\end{array}$} & \multicolumn{3}{|c|}{ Co loading [wt \% $]^{[\mathrm{b}]}$} \\
\hline & Total $^{[c]}$ & Mesopore ${ }^{[\mathrm{d}]}$ & Total $^{[\mathrm{e}]}$ & Micropore $^{[f]}$ & Mesopore ${ }^{[g]}$ & & Co & $\mathrm{Ru}$ & $\mathrm{Zr}$ \\
\hline $\mathrm{Co} / \mathrm{SiO}_{2}$ & 200 & 180 & 0.89 & 0.01 & 0.88 & 16 & 18.6 & n.a. & n.a. \\
\hline $\mathrm{Co} / m e s o \mathrm{H}-\mathrm{ZSM}-5(\mathrm{o})$ & 440 & 270 & 0.45 & 0.07 & 0.38 & 11 & 20.7 & n.a. & n.a. \\
\hline $\mathrm{Co} / m e s o \mathrm{H}-\mathrm{ZSM}-5$ & 510 & 310 & 0.50 & 0.08 & 0.41 & 10 & 23.8 & n.a. & n.a. \\
\hline 10 wt $\% \mathrm{Co} / m e s o \mathrm{H}-\mathrm{ZSM}-5$ & 560 & 370 & 0.55 & 0.08 & 0.47 & 10 & 10.7 & n.a. & n.a. \\
\hline $\mathrm{CoRu} / m e s o \mathrm{H}-\mathrm{ZSM}-5$ & 460 & 290 & 0.40 & 0.07 & 0.33 & 10 & 17.7 & 0.3 & n.a. \\
\hline $\mathrm{Co} / \mathrm{ZrO}_{2} /$ mesoH-ZSM-5 & 420 & 260 & 0.37 & 0.07 & 0.30 & 12 & 18.0 & n.a. & 3.5 \\
\hline $\mathrm{CoRu} / \mathrm{ZrO}_{2} /$ mesoH-ZSM-5 & 430 & 270 & 0.39 & 0.07 & 0.32 & 13 & 17.8 & 0.3 & 3.7 \\
\hline
\end{tabular}

[a] Co crystallite size calculated by using $d\left(\mathrm{CO}^{0}\right)=0.75 \times d\left(\mathrm{CO}_{3} \mathrm{O}_{4}\right)$, in which $d\left(\mathrm{Co}_{3} \mathrm{O}_{4}\right)$ is determined from XRD analysis by applying the Scherrer equation; [b] Obtained from ICP-OES; [c] BET surface area; [d] Mesopore surface area obtained by using the $t$-plot method applied to the $\mathrm{N}_{2}$ isotherm; [e] Total pore volume; [f] Micropore volume obtained by using the $t$-plot method; [g] Mesopore volume calculated as $V_{\text {meso }}=V_{\text {total }}-V_{\text {micro. }}$. hydrogen consumption above $900 \mathrm{~K}$ has decreased upon $\mathrm{ZrO}_{2}$ addition. These results reveal that the reducibility of $\mathrm{Co}$ is lower over H-ZSM-5 than over amorphous $\mathrm{SiO}_{2}$ owing to a stronger metal-support interaction. In addition, the presence of multiple reduction peaks on zeolite-supported catalysts indicates Co species with different reactivities.

Degrees of reduction, as calculated from the total consump-
(4.6 wt \% Zr). Moreover, a shoulder appears at approximately $550 \mathrm{~K}$, which indicates a considerable increase in the Lewis acidity of this sample owing to the presence of $\mathrm{ZrO}_{2}{ }^{[18]}$ (Figure 1).

All the mesoporous supports given in Table 1 were loaded with $18-24 \mathrm{wt} \%$ of Co (Table 3), except $10 \mathrm{wt} \% \mathrm{Co} / \mathrm{mesoH}$ ZSM-5, which was prepared with a lower Co loading of $10.7 \mathrm{wt} \%$. In addition, $0.3 \mathrm{wt} \%$ Ru-promoted catalysts were prepared over mesoH-ZSM-5 and $\mathrm{ZrO}_{2} /$ mesoH-ZSM-5 supports. The $\mathrm{N}_{2}$ physisorption results reveal that at least $70 \%$ of the micropore volume is maintained after the impregnation of the active phase (cf. Tables 1 and 3).

The average Co crystallite size, as calculated from the XRD data, is the largest for $\mathrm{Co} / \mathrm{SiO}_{2}(16 \mathrm{~nm})$ and similar for all zeolite-supported catalysts (10-13 nm) (Table 3). According to TEM analysis, Co particles form clusters over amorphous $\mathrm{SiO}_{2}$, which results in an inhomogeneous distribution of the FTS active phase on this support (Figure $2 \mathrm{a}$ ). This spatial distribution is to some extent improved in the zeolite-supported catalysts; yet, regions with higher Co concentration can be observed in all the TEM micrographs (Figure $2 b-d$ ).

The dark-field TEM images (Figure 3) of $\mathrm{Co} / \mathrm{SiO}_{2}$ and mesoHZSM-5 supports show smaller Co particles that are dispersed more over mesoH-ZSM-5 than over $\mathrm{Co} / \mathrm{SiO}_{2}$. Any Co particle can hardly be observed at the outer surface (edge) of the zeolite crystallites, which indicates that most of the FTS active phase is introduced into the mesopore space of mesoH-ZSM-5.

The temperature-programmed reduction by $\mathrm{H}_{2}\left(\mathrm{TPR}-\mathrm{H}_{2}\right)$ profiles of supported $\mathrm{Co}$ catalysts are shown in Figure 4. The classical two-step reduction of $\mathrm{CO}_{3} \mathrm{O}_{4}$ via $\mathrm{CoO}$ to $\mathrm{Co}^{\text {[[19] }}$ occurs for $\mathrm{Co} / \mathrm{SiO}_{2}$ below $800 \mathrm{~K}$. A sharp peak at approximately $550 \mathrm{~K}$ is also observed in the profile of $\mathrm{Co} / \mathrm{mesoH}-\mathrm{ZSM}-5$, which is followed by two broad peaks: one at $600-900 \mathrm{~K}$ and the other above $900 \mathrm{~K}$. The latter two peaks merge in the case of CoRu/ mesoH-ZSM-5 and form a large peak at approximately $700 \mathrm{~K}$ with a shoulder at approximately $600 \mathrm{~K}$. Moreover, the onset temperature of reduction and the positions of the peak maxima shift by approximately $100 \mathrm{~K}$ to lower temperatures, which suggests that the presence of Ru increases the rate of Co reduction. $\mathrm{Co} / \mathrm{ZrO}_{2} /$ mesoH-ZSM-5 demonstrates a pattern similar to that of $\mathrm{Co} / \mathrm{mesoH}-\mathrm{ZSM}-5$, although it is apparent that
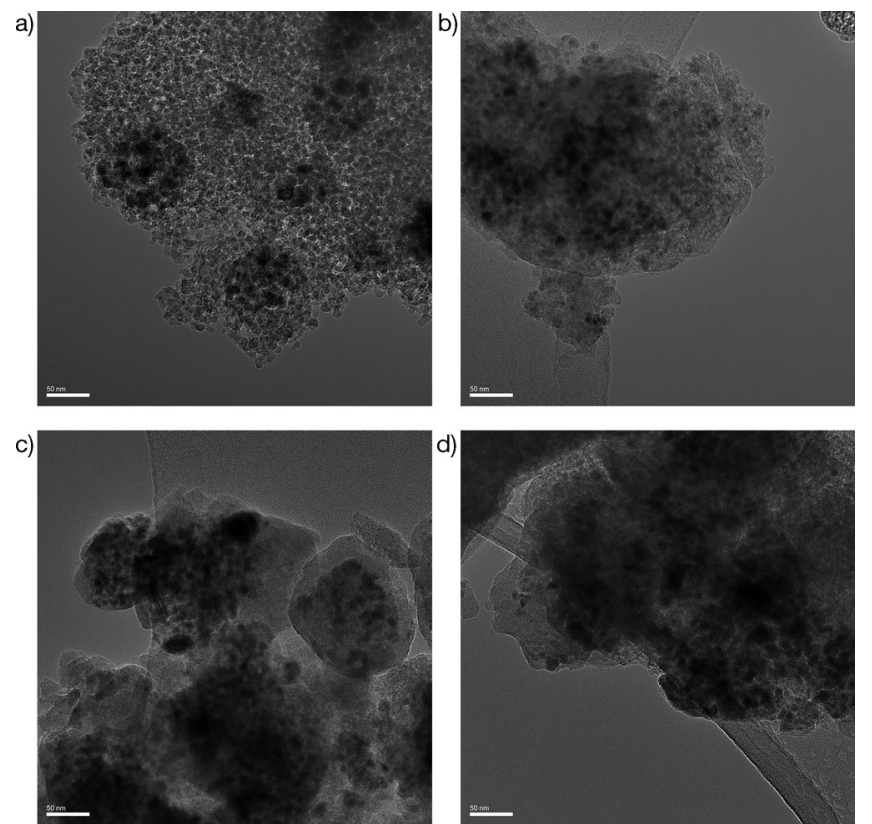

Figure 2. Quasi in situ TEM images of FTS catalysts after reduction in $\mathrm{H}_{2}$ at $773 \mathrm{~K}$ for $13 \mathrm{~h}$. Scale bars $=50 \mathrm{~nm}$.

tion of $\mathrm{H}_{2}$, are listed in Table 4. Co is fully reduced over $\mathrm{SiO}_{2}$, whereas the degree of reduction is $67 \%$ for $\mathrm{Co} / \mathrm{mesoH}-\mathrm{ZSM}-5$. With the addition of either $\mathrm{Ru}$ or $\mathrm{ZrO}_{2}$, this value increases considerably and reaches above $90 \%$. Different mechanisms have been proposed for the promoting effects of precious metals (Ru) and $\mathrm{ZrO}_{2}$. Small amounts of $\mathrm{Ru}$ in the catalyst composition promote $\mathrm{H}_{2}$ spillover and thus increase the rate of reduction. ${ }^{[20]}$

\begin{tabular}{|c|c|}
\hline Catalyst & Degree of reduction [\%] \\
\hline $\mathrm{Co} / \mathrm{SiO}_{2}$ & $>95$ \\
\hline $\mathrm{Co} / m e s o \mathrm{H}-\mathrm{ZSM}-5$ & 67 \\
\hline CoRu/mesoH-ZSM-5 & 92 \\
\hline $\mathrm{Co} / \mathrm{ZrO}_{2} /$ mesoH-ZSM-5 & $>95$ \\
\hline $\mathrm{CoRu} / \mathrm{ZrO}_{2} /$ mesoH-ZSM-5 & $>95$ \\
\hline
\end{tabular}



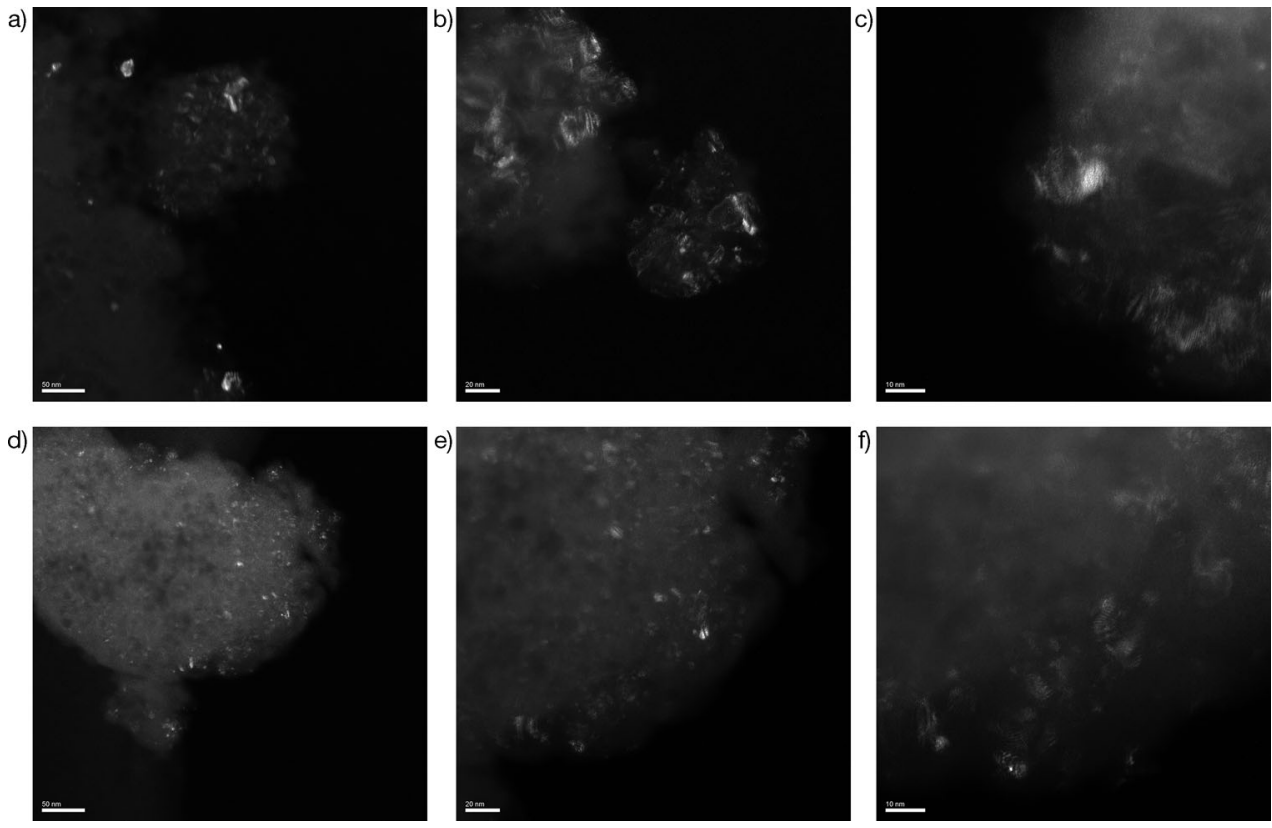

Figure 3. $a, b, c)$ Quasi in situ dark-field TEM images of $\mathrm{Co} / \mathrm{SiO}_{2}$ and $\left.\mathrm{d}, \mathrm{e}, \mathrm{f}\right) \mathrm{Co} / \mathrm{mesoH}-\mathrm{ZSM}-5$, both after reduction in $\mathrm{H}_{2}$ at $773 \mathrm{~K}$ for $13 \mathrm{~h}$. Scale bars $\left.\left.=\mathrm{a}, \mathrm{d}\right) 50 \mathrm{~nm}, \mathrm{~b}, \mathrm{e}\right) 20 \mathrm{~nm}$, and c, f) $10 \mathrm{~nm}$.
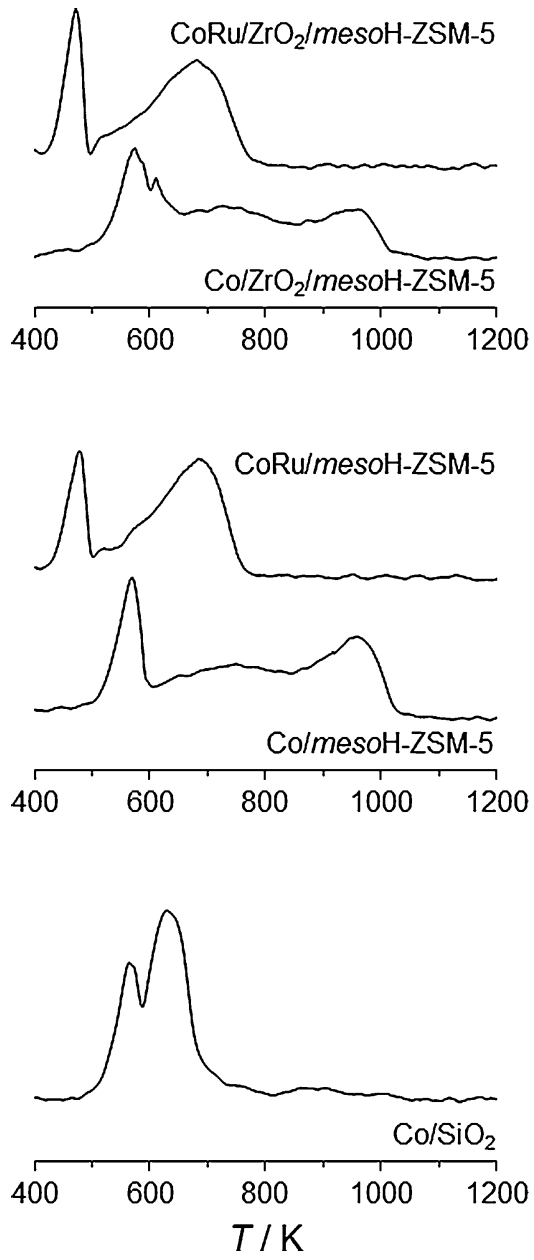

Figure 4. TPR- $\mathrm{H}_{2}$ profiles $\left(5 \mathrm{Kmin}^{-1}\right)$ of fresh catalysts for FTS.
$\mathrm{ZrO}_{2}$ forms an intermediate layer between the metal and the support, which reduces the metalsupport interaction. ${ }^{[21]}$ Such mechanistic differences are indicated by the observed changes in the TPR- $\mathrm{H}_{2}$ profiles of $\mathrm{CoRu} /$ mesoH-ZSM-5 and $\mathrm{Co} / \mathrm{ZrO}_{2} /$ mesoH-ZSM-5 compared with those of $\mathrm{Co} / \mathrm{mesoH}-\mathrm{ZSM}-5$.

The reducibility and coordination of Co on zeolite-supported catalysts were also studied by using X-ray absorption spectroscopy (XAS). The extended X-ray absorption fine structure (EXAFS) Fourier transform and X-ray absorption near-edge structure (XANES) spectra of fresh and activated catalysts as well as reference compounds at Co K-absorption edges are shown in Figure 5.

The EXAFS data of fresh (supported) Co species are characterized by the presence of two peaks, which are characteristic of $\mathrm{Co}-\mathrm{O}$ and $\mathrm{Co}-\mathrm{Co}$ coordination, respectively. The $\mathrm{Co}-\mathrm{O}$ coordination can still be observed in the EXAFS spectrum of the activated $\mathrm{Co} / \mathrm{mesOH}-\mathrm{ZSM}-5$ catalyst, demonstrating an incomplete reduction of $\mathrm{Co}$, which is in agreement with the TPR- $\mathrm{H}_{2}$ results. In contrast, activated $\mathrm{Co} / \mathrm{ZrO}_{2} /$ mesoH-ZSM-5, CoRu/ $\mathrm{ZrO}_{2} /$ mesoH-ZSM-5, and $\mathrm{CoSiO}_{2}$ catalysts all have a local atomic structure similar to that of the Co foil, which confirms a full reduction of Co.

The XANES spectra of $\mathrm{Co} / \mathrm{ZrO}_{2} /$ mesoH-ZSM-5 and CoRu/ $\mathrm{ZrO}_{2} /$ mesoH-ZSM- 5 are characterized by a pre-edge peak at approximately $7710 \mathrm{eV}$, arising from the $1 \mathrm{~s} \rightarrow 3 \mathrm{~d}$ transition, which is only quadrupole allowed for coordination sites without centric symmetry, and an edge peak at $7717 \mathrm{eV}^{[22]}$ According to the edge position, $\mathrm{CO}_{3} \mathrm{O}_{4}$ is the major $\mathrm{Co}$ phase in these promoted catalysts; this observation is in agreement with the XRD and TPR- $\mathrm{H}_{2}$ results. After activation, the XANES spectra of $\mathrm{Co} /$ $\mathrm{ZrO}_{2} /$ mesoH-ZSM-5 and $\mathrm{CoRu} / \mathrm{ZrO}_{2} /$ mesoH-ZSM-5 resemble that of the Co foil. The slight difference can be due to the metal-support interactions that can induce a perturbation on the electronic structure and hence on the spectral features. ${ }^{[22 c]}$

The results obtained from XAS are consistent with the improved reducibility and degree of reduction of Co upon promotion with $\mathrm{ZrO}_{2}$ (Table 4), which reveal that $\mathrm{Ru}$ addition to the $\mathrm{ZrO}_{2}$-promoted catalyst is not necessary for activation temperatures above $773 \mathrm{~K}$.

\section{Catalytic performance}

Lower hydrocarbons (C3-C5) are detected in the product streams upon feeding $\mathrm{C} 6$ (in a mixture with $\mathrm{H}_{2}$ ) over meso $\mathrm{H}$ ZSM-5 (Figure 6). C6 conversion increases from $4 \%$ to $96 \%$ if $n$-hexane is replaced by 1 -hexene in the feed stream. This dif- 
a)

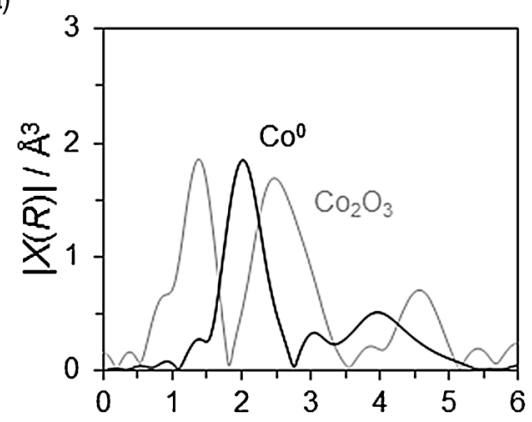

b)

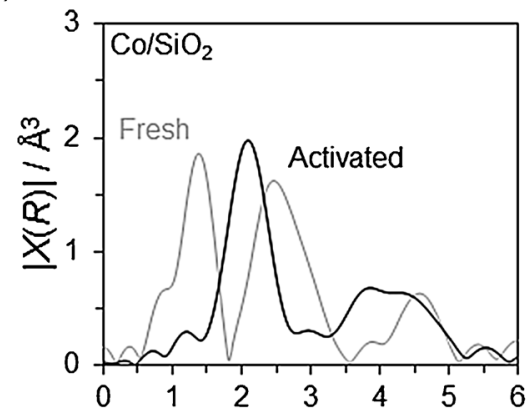

c)

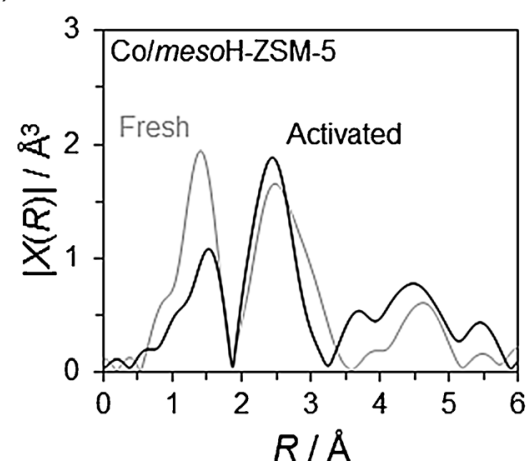

d)

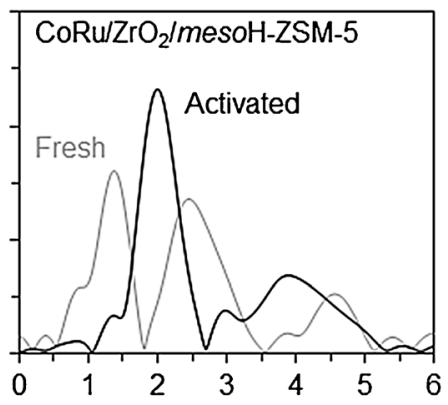

e)

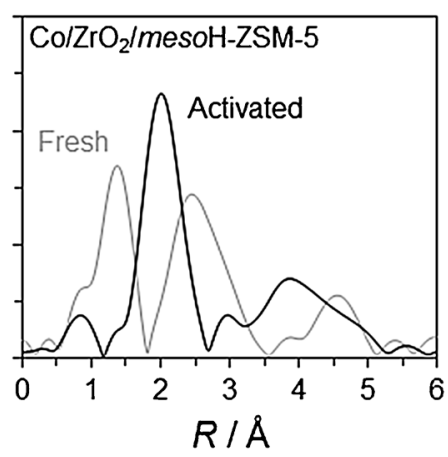

f)

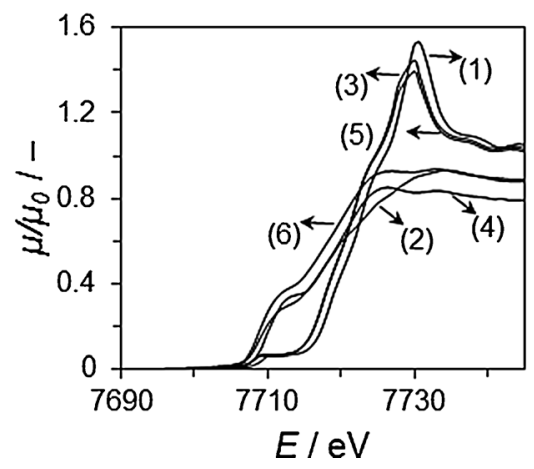

Figure 5. a-e) Fourier-transformed EXAFS (Co K-edge, not phase corrected) and f) XANES spectra of fresh and activated catalysts for FTS (reduced quasi in situ in $\mathrm{H}_{2}$ ). Spectra f correspond to $\mathrm{Co}_{2} \mathrm{O}_{3}(1), \mathrm{Co}^{0}(2)$, fresh $\mathrm{Co} / \mathrm{ZrO}_{2} /$ mesoH-ZSM-5 (3), activated $\mathrm{Co} / \mathrm{ZrO}_{2} /$ mesoH-ZSM-5 (4), fresh $\mathrm{CoRu} / \mathrm{ZrO}_{2} /$ mesoH-ZSM-5 (5), and activated CoRu/ $\mathrm{ZrO}_{2} /$ mesoH-ZSM-5 (6).

ference in conversion implies that olefins are much more reactive in the acid-catalyzed reactions over the zeolite support. Hydrocarbon conversion reactions over mesoH-ZSM-5 do not lead to methane formation. However, nearly full conversion of $n$-hexane and a $99 \%$ methane selectivity are obtained by incorporating $\mathrm{Co}$ into mesoH-ZSM-5. These results reveal that hydrocarbon hydrogenolysis is predominant over Co.

In FTS, the cobalt time yield (CTY) of $\mathrm{Co} / \mathrm{mesoH}^{-\mathrm{ZSM}-5}$ is almost two times higher than that of $\mathrm{Co} / \mathrm{SiO}_{2}$ (Figure 7). At the same time, calculations assuming spherical Co particles with diameters equal to those reported in Table 3 show that the ratio of $\mathrm{CO}$ turnover frequencies between $\mathrm{Co} / \mathrm{mesoH}-\mathrm{ZSM}-5$ and $\mathrm{Co} / \mathrm{SiO}_{2}$ is approximately 1.1 , which is in line with the general belief that Co-based FTS is not structure sensitive if particles are larger than $6-10 \mathrm{~nm}^{[23]}$ The initial activity of Co/ mesoH-ZSM-5 increases with the addition of either $\mathrm{Ru}$ or $\mathrm{ZrO}_{2}$ to the catalyst composition. However, CTYs of all the zeolitesupported catalysts become similar after approximately $80 \mathrm{~h}$ on stream.

The carbon selectivities to different FTS product ranges over promoted and unpromoted catalysts are shown in Figure 8. Under the applied process conditions, $\mathrm{Co} / \mathrm{SiO}_{2}$ is highly selective to $\mathrm{C} 21+$ (wax). Wax production is suppressed considerably over the zeolite-containing catalysts, which results in higher carbon selectivity toward gasoline range hydrocarbons (C5C11) as well as to C1. A comparison of $\mathrm{Co} / \mathrm{mesoH}-\mathrm{ZSM}-5$ and $\mathrm{CoRu} / \mathrm{mesoH}-\mathrm{ZSM}-5$ catalysts under isoconversion conditions shows a minor effect of $\mathrm{Ru}$ in terms of altering the catalyst product distribution (Figure 8). In general, the selectivity toward C1 $\left(S_{C_{1}}\right)$ decreases only slightly by introducing $\mathrm{Ru}$ and/or $\mathrm{ZrO}_{2}$.

A detailed analysis of liquid products formed over Co/ mesoH-ZSM-5 (in the FTS reaction) shows a large fraction of unsaturated hydrocarbons, other than $\alpha$-olefins, in the sample (Figure 9). (Notably, a contribution of aromatics plus oxygenates to the liquid products was $<0.3$ wt \%.)

The time on stream (TOS) evolution of $\mathrm{CO}$ conversion $\left(X_{\mathrm{CO}}\right)$ during $140 \mathrm{~h}$ on stream demonstrates that the stability of $\mathrm{Co} /$ mesoH-ZSM-5 in terms of activity is comparable to that of $\mathrm{Co} /$ $\mathrm{SiO}_{2}$ (Figure 10). Methane selectivity is fairly constant over Co/ $\mathrm{SiO}_{2}$ during $140 \mathrm{~h}$ on stream ( $\approx 6 \%$ ), whereas it increases from 11 to $14 \%$ with time as $X_{\text {CO }}$ decreases by $9 \%$ over $\mathrm{Co} / \mathrm{mesoH}^{-}$ $\mathrm{ZSM}-5$. Once the catalytic activity is restored after regeneration, $\mathrm{S}_{\mathrm{C} 1}$ decreases again (Figure 10). In contrast to $\mathrm{Co} / \mathrm{mesoH}-\mathrm{ZSM}$ 5 , no $\mathrm{C} 4$ isomers are produced over $\mathrm{Co} / \mathrm{SiO}_{2}$. The iso-to-normal $\mathrm{C} 4$ ratio (I/N (C4)) over the former catalyst decreases with TOS and reaches a steady-state level after approximately $80 \mathrm{~h}$ on stream. The I/N (C4) of the reactivated catalyst is similar to that of the fresh catalyst, which indicates that the acid sites are recovered.

To investigate the effect of conversion level on $S_{\mathrm{C} 1}$ over the zeolite-supported catalyst, $X_{\mathrm{CO}}$ was varied by changing the space velocities at different $\mathrm{H}_{2} / \mathrm{CO}$ ratios of 1 and 2 . Data reported in Table 5 indicate that increasing the $\mathrm{H}_{2}$ concentration 


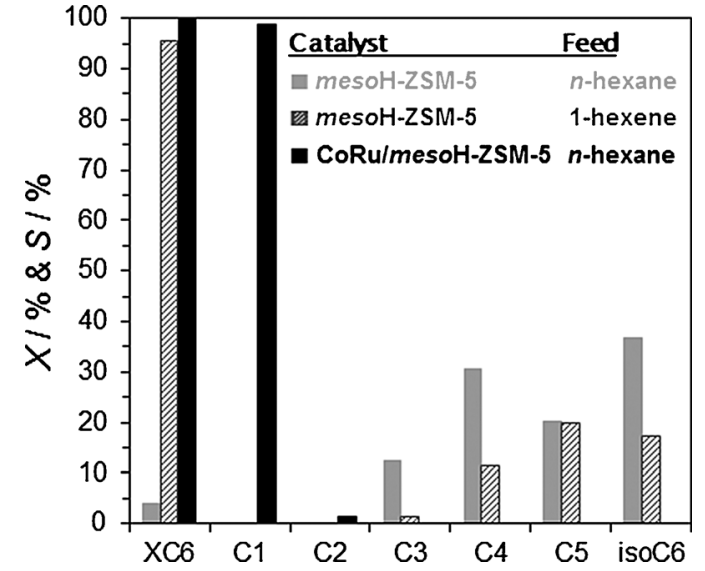

Figure 6. Conversion and product selectivities in $\mathrm{C} 6$ hydroconversion over mesoH-ZSM-5 and CoRu/mesoH-ZSM-5. Data were collected after $20 \mathrm{~h}$ on stream at $513 \mathrm{~K}, 15$ bar, $\mathrm{H}_{2} / \mathrm{C} 6=9.0, \mathrm{~N}_{2} / \mathrm{H}_{2}=2.0$, and $\mathrm{SV}=13 \mathrm{~mol}_{\mathrm{C} 6} \mathrm{~kg}_{\mathrm{cat}}^{-1} \mathrm{~h}^{-1}$. Either $n$-hexane or 1 -hexene was included in the feed stream, as indicated in the legend.

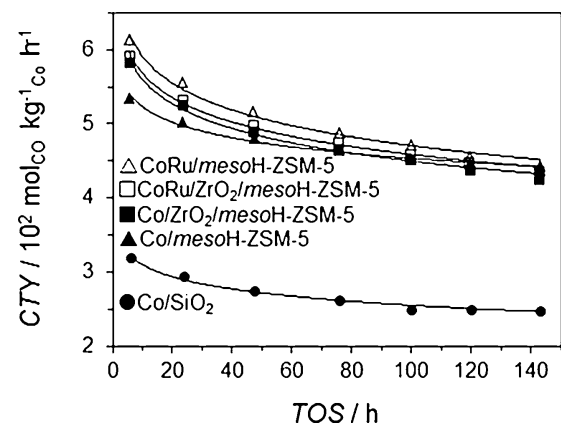

Figure 7. TOS evolution of the CTY during FTS at $513 \mathrm{~K}, 15 \mathrm{bar}, \mathrm{H}_{2} / \mathrm{CO}=1$, and GHSV $=12 \mathrm{~m}_{\text {STP }}^{3} \mathrm{~kg}_{\text {cat }}^{-1} \mathrm{~h}^{-1}$.

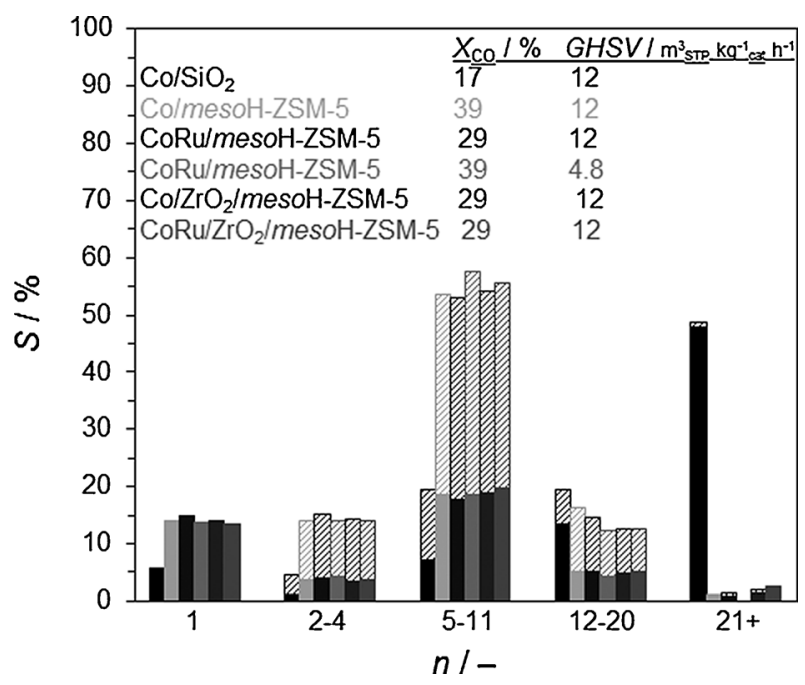

Figure 8. Carbon selectivity toward products of FTS after $140 \mathrm{~h}$ on stream. In each carbon number group from left to right: $\mathrm{Co} / \mathrm{SiO}_{2}, \mathrm{Co} / m e s o \mathrm{H}-\mathrm{ZSM}-5$, $\mathrm{CoRu} / \mathrm{mesoH}-\mathrm{ZSM}-5$, CoRu/mesoH-ZSM-5, $\mathrm{Co} / \mathrm{ZrO}_{2} / \mathrm{mesoH}^{-\mathrm{ZSM}}-5$, and $\mathrm{CoRu} /$ $\mathrm{ZrO}_{2} /$ mesoH-ZSM-5. Experiments were performed at $513 \mathrm{~K}, 15$ bar, and $\mathrm{H}_{2} /$ $\mathrm{CO}=1$.

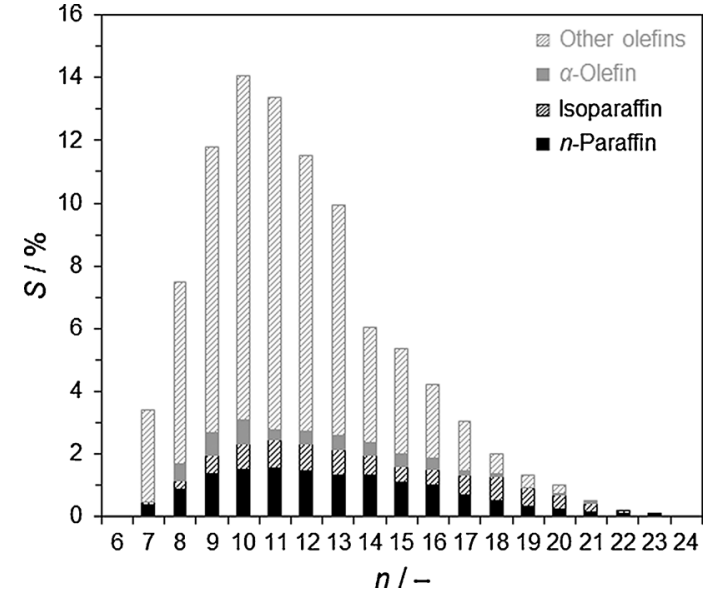

Figure 9. Selectivity distribution of liquid hydrocarbons formed over $\mathrm{Co} /$ mesoH-ZSM-5. Liquid products were collected after $140 \mathrm{~h}$ on stream at $513 \mathrm{~K}, 15$ bar, $\mathrm{H}_{2} / \mathrm{CO}=1, \mathrm{GHSV}=12 \mathrm{~m}_{\mathrm{STP}}^{3} \mathrm{~kg}_{\mathrm{cat}}^{-1} \mathrm{~h}^{-1}$ and were analyzed by $2 \mathrm{D}$ GC. The associated 2D chromatogram is presented in Figure S2.
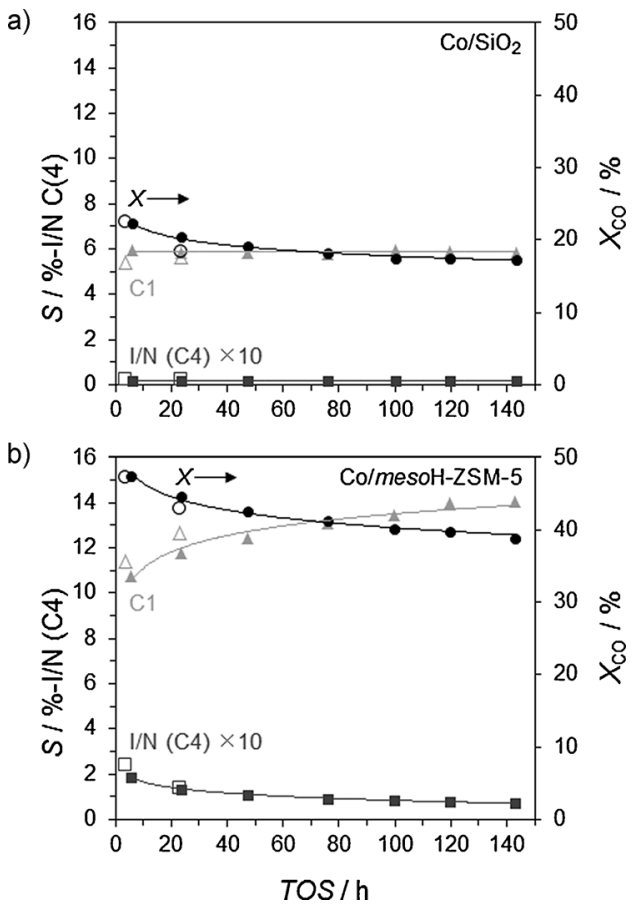

Figure 10. TOS evolution of CO conversion $\left(X_{\mathrm{CO}}\right)$, methane $(C 1)$ selectivity, and $\mathrm{I} / \mathrm{N}$ (C4) over a) $\mathrm{Co} / \mathrm{SiO}_{2}$ and b) $\mathrm{Co} / \mathrm{mesoH}^{-Z S M}-5$ during FTS at $513 \mathrm{~K}$, 15 bar, $\mathrm{H}_{2} / \mathrm{CO}=1$, and GHSV $=12 \mathrm{~m}_{\text {STP }}^{3} \mathrm{~kg}_{\text {cat }}^{-1} \mathrm{~h}^{-1}$. Solid symbols correspond to the first reaction run; open symbols correspond to the second reaction run over in situ reactivated catalysts (in $\mathrm{H}_{2}$ at $773 \mathrm{~K}$ for $13 \mathrm{~h}$ ).

Table 5. CO conversion and carbon selectivity to products of FTS over $\mathrm{Co} / \mathrm{mesoH}-\mathrm{ZSM}-5$ after $22 \mathrm{~h}$ on stream at $513 \mathrm{~K}, 15$ bar total pressure, and different feed composition $\mathrm{H}_{2} / \mathrm{CO}$ ratios and space velocities.

\begin{tabular}{|lllllllll|}
$\mathrm{H}_{2} / \mathrm{CO}$ & $\begin{array}{l}\mathrm{GHSV} \\
{\left[\mathrm{m}_{\text {STP }}^{3} \mathrm{~kg}_{\text {cat }}^{-1}\right]}\end{array}$ & $\begin{array}{l}X_{\mathrm{CO}} \\
{[\%]}\end{array}$ & $\mathrm{C} 1$ & $\mathrm{C} 2-\mathrm{C} 4$ & $\mathrm{C} 5-\mathrm{C} 11$ & $\mathrm{C} 12-\mathrm{C} 20$ & $\mathrm{C} 21+$ & $\mathrm{CO}_{2}$ \\
\hline 1 & 4.8 & 48 & 10 & 12 & 62 & 12 & 1 & 3 \\
1 & 12 & 42 & 12 & 14 & 56 & 16 & 1 & 1 \\
2 & 12 & 83 & 17 & 15 & 51 & 15 & 0 & 2 \\
2 & 24 & 55 & 20 & 17 & 48 & 14 & 0 & 1 \\
\hline
\end{tabular}


by changing the $\mathrm{H}_{2} / \mathrm{CO}$ ratio from 1 to 2 results in $5-10 \%$ increase in $S_{\mathrm{C}_{1}}$. Furthermore, this value is higher at lower $X_{\mathrm{cO}}$ for both $\mathrm{H}_{2} / \mathrm{CO}$ ratios.

\section{Discussion}

The acid-catalyzed hydroconversion of $\mathrm{C} 6$ confirms that hydrocracking is feasible under the applied LTFT process conditions (Figure 6), which is consistent with the literature. ${ }^{[\mathrm{bb}, 8 \mathrm{a}]}$ This finding explains the increased selectivities to liquid fractions over the $\mathrm{H}-\mathrm{ZSM}-5$-containing catalysts (Figure 8). A close contact between the metal for FTS and acid sites is reported to be of crucial importance in this respect: ${ }^{[11]}$ if acid site domains are in the vicinity of FTS sites at a nanometer scale, $\alpha$-olefins, which are the primary products of FTS, may crack or isomerize before they are hydrogenated. The closer these sites, the higher the probability for cracking to occur. The conversion of 1-hexene is much higher than that of $n$-hexane over mesoH-ZSM-5 (Figure 6). The classical mechanism of such acid-catalyzed reactions, through the rearrangement of a secondary carbocation into a protonated dialkylcyclopropane, increases the degree of branching of hydrocarbons. ${ }^{[24]}$ Because FTS may mainly produce linear $\alpha$-olefins, a considerable fraction of other unsaturated hydrocarbons shown in Figure 9 are formed over the acid sites.

Ru has (de)hydrogenation activity, which promotes the acidcatalyzed hydrocarbon reactions. ${ }^{[25]}$ At the same time, Ru increases the reducibility of small Co particles (Figure 4), which are active for hydrogenolysis. ${ }^{[26]}$ Thus, Ru promotes hydrogenolysis (indirectly) and, in the absence of $\mathrm{CO}$, this reaction over the $20 \mathrm{wt} \%$ Co catalyst is prevalent (Figure 6). As a consecutive reaction, hydrogenolysis may even convert the products of the acid-catalyzed reactions into $\mathrm{C} 1$ (and $\mathrm{C} 2$ ).

The higher activity of $\mathrm{Co} / \mathrm{mesoH}-\mathrm{ZSM}-5$ compared with that of $\mathrm{Co} / \mathrm{SiO}_{2}$ (Figures 7 and 10 ) is a result of a smaller Co crystallite size (Table 3 and Figure 3 ). Both catalysts demonstrate a similar TOS stability in terms of CO conversion. Sintering is an important cause for the deactivation of Co-based catalysts for $\mathrm{FTS}^{[27]}$ and can be suppressed by maximizing the spatial distribution of active phase particles over the support surface. ${ }^{[27 b, 28]}$ Therefore, the availability of accessible surface area is an advantage in the design of stable catalysts (supported on mesoporous H-ZSM-5) for FTS. ${ }^{[13 a]}$ The representative TEM images in Figures 2 and 3 show that the Co distribution in the mesopores of the hierarchical zeolite is slightly better than that in amorphous $\mathrm{SiO}_{2}$.

The TPR- $\mathrm{H}_{2}$ and EXAFS results (Figure 5) reveal that the addition of promoters ( $\mathrm{Ru}$ and/or $\mathrm{ZrO}_{2}$ ) increases the reducibility and degree of reduction of smaller cobalt oxide crystallites over mesoH-ZSM-5. Although large Co particles do not reoxidize in the FTS reaction environment, the reoxidation of smaller crystallites $(<4 \mathrm{~nm})$ starts in an early course of the reaction. ${ }^{[29]}$ Therefore, the CTY of the promoted catalysts, which is initially higher, reaches values similar to that of the unpromoted catalysts after a gradual decrease (Figure 7). The fact that both $\mathrm{Co} /$ $\mathrm{ZrO}_{2} /$ mesoH-ZSM-5 and $\mathrm{CoRu} / \mathrm{ZrO}_{2} /$ mesoH-ZSM-5 (with similar Co loadings and crystallite sizes; Table 3) present fairly identical values and trends in the TOS evolution of CTY (Figure 7) supports the EXAFS data in the sense that the addition of $\mathrm{ZrO}_{2}$ is sufficient to fully reduce $\mathrm{Co}$ by using the activation method.

The carbon selectivity toward $\mathrm{C} 1$ over $\mathrm{Co} / \mathrm{mesoH}_{-} \mathrm{ZSM}-5$ is more than two times larger than that over $\mathrm{Co} / \mathrm{SiO}_{2}$ (Figure 8). The possible sources for such a high methane selectivity are as follows: (1) a poor catalyst reducibility, (2) a low chain growth probability $(\alpha)$ in FTS, (3) acid-catalyzed hydroconversion reactions, and (4) side reactions over Co. Sources 1 and 2 increase the rate of methane formation through FTS, whereas in the case of sources 3 and 4, other reactions generate C1 along with FTS. The contribution of each source is discussed below:

1) Figure 8 shows that promoter addition and reducibility enhancement do not significantly change the methane selectivity.

2) In line with previous reports, ${ }^{[11,13-14]}$ the fractional molar distribution of products of FTS has a nonlinear shape for the $\mathrm{H}$-ZSM-5-containing catalysts (Figure S3a). The only exception is Co/mesoH-ZSM-5(o), which is devoid of strong Brønsted acidity (Figure 1) and represents a linear ASF product distribution, which is similar to the case of $\mathrm{Co} / \mathrm{SiO}_{2}$. A "break" in the ASF product selectivity at about C12 (Figure S3 a) can be translated into a lower $\alpha$ for higher hydrocarbons, which can eventually increase the formation of methane. The $S_{\mathrm{C} 1}$ of $\mathrm{Co} /$ mesoH-ZSM-5 is $2 \%$ higher than

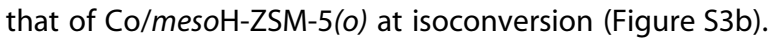

3) No methane was detected during the conversion of $\mathrm{C} 6$ over the bare zeolite (Figure 6), which agrees with the general belief that the (hydro)cracking mechanism over acid sites does not lead to $\mathrm{C} 1{ }^{[24]}$ Furthermore, if overcracking inside the zeolite pores was the main origin of the large production of methane over the Co-containing catalysts, then $\mathrm{Co} / \mathrm{mesoH}_{\mathrm{Z}} \mathrm{ZSM}-5$ (o) should have represented a much lower carbon selectivity toward $\mathrm{C} 1$. However, the catalytic performance results shown in Figure $\mathrm{S} 3$ rule out this possibility. Therefore, alleviating the effect of the above-mentioned sources (1-3) may lower $S_{\mathrm{C} 1}$ (over $\mathrm{Co} /$ mesoH-ZSM-5) only by a few percent at maximum.

4) Among Fe and Co, the hydrogenation activity of $\mathrm{Co}$ is stronger. ${ }^{[30]}$ The Co-based catalysts for FTS are more sensitive (than $\mathrm{Fe}$ ) to changes in the process conditions ${ }^{[30]}$ (such as temperature and $\mathrm{H}_{2} / \mathrm{CO}$ ratio). Moreover, the $\mathrm{C} 1$ level is typically higher for Co-based catalysts than what is anticipated by extrapolating the ASF distribution to $n=1$ (Figure S3a). In the case of our zeolite-supported Co catalysts, both direct $\mathrm{CO}$ hydrogenation to methane $\left(\mathrm{CO}+3 \mathrm{H}_{2} \rightarrow\right.$ $\mathrm{CH}_{4}+\mathrm{H}_{2} \mathrm{O}$ ) and hydrogenolysis are expected to occur because both side reactions become important on smaller $\mathrm{Co}$ particles. This is a result of the larger $\mathrm{H}_{2}$ coverage over lower index surface crystallographic planes or steps and corners $^{[31]}$ (of which the density increases as Co crystallite size decreases). ${ }^{[32]}$ Hydrogenolysis is a structure-sensitive reaction that will compete with direct $\mathrm{CO}$ hydrogenation over the small metal particles. ${ }^{[33]}$ Although this reaction could be suppressed at low CO conversions owing to competitive $\mathrm{CO}$ adsorption, ${ }^{[34]}$ it can be observed from Figure 6 
that in the absence of $\mathrm{CO}$, the zeolite-supported Co converts hydrocarbons into methane in a yield of $99 \%$ at $513 \mathrm{~K}$.

In line with our previously reported $\mathrm{CO}$ adsorption results, ${ }^{[13 b]}$ the TPR- $\mathrm{H}_{2}$ results reveal that the nature and thus the reactivity of Co sites is more heterogeneous over the zeolitesupported catalysts than over $\mathrm{Co} / \mathrm{SiO}_{2}$ (Figure 4). We conclude that owing to the strong Co-zeolite interaction (Figure 4), lower coordinated Co sites are stabilized over the zeolite support. Therefore, this catalyst is sensitive to changes in $\mathrm{H}_{2}$ concentration as well and demonstrates an increased selectivity toward $\mathrm{C} 1$ as the $\mathrm{H}_{2}$ concentration is higher at lower conversion levels (Table 5). This observation explains why in contrast to $\mathrm{Co} / \mathrm{SiO}_{2}, \mathrm{~S}_{\mathrm{C} 1}$ increases with time over $\mathrm{Co} /$ mesoH-ZSM-5 with a decrease in $\mathrm{CO}$ conversion (Figure 10).

At similar conversion levels, a catalyst with a lower Co loading of $10.7 \mathrm{wt} \%$ has $4 \%$ more selectivity toward C1 (Figure $\mathrm{S} 3 \mathrm{~b}$ ). At a lower Co loading, more defects are expected on the metal crystallites; therefore, this result further confirms the above-mentioned hypothesis on the main source of methane formation over the zeolite-supported Co catalysts.

\section{Conclusions}

Mesoporous H-ZSM-5 (mesoH-ZSM-5) is prepared through base and acid treatments of a commercial ZSM-5 zeolite $(\mathrm{Si} / \mathrm{Al}=40)$. The base treatment with tetrapropylammonium hydroxide increases the mesopore surface area considerably and deactivates the Brønsted acidity of the zeolite. The decreased Si/Al ratio, caused by zeolite desilication, is set back to the original value through the succeeding treatment with $\mathrm{HNO}_{3}$, which also regenerates the Brønsted acidity. If loaded with $\mathrm{Co}$, the resulting mesoH-ZSM-5-supported Co catalyst is much more active than the conventional $\mathrm{Co} / \mathrm{SiO}_{2}$ catalyst. After $140 \mathrm{~h}$ on stream, $\mathrm{Co} / \mathrm{mesoH}-\mathrm{ZSM}-5$ is three times more selective to the $\mathrm{C} 5-\mathrm{C} 11$ fraction than is $\mathrm{Co} / \mathrm{SiO}_{2}$. A large contribution of unsaturated hydrocarbons, other than $\alpha$-olefins, to the liquid products as well as the conversion of $n$-hexane and 1-hexane indicate that the improved selectivity toward the gasoline fraction owes to the secondary acid-catalyzed reactions of FischerTropsch $\alpha$-olefins over the zeolite.

With the addition of either $\mathrm{Ru}$ or $\mathrm{ZrO}_{2}$ promoters, the reducibility of zeolite-supported Co increases considerably, which leads to an increased initial catalytic activity. Nevertheless, promoters do not affect the product distribution significantly. The TPR- $\mathrm{H}_{2}$ and $\mathrm{CO}$ adsorption results reveal that the reactivity of $\mathrm{Co}$ is diverse as supported on mesoporous $\mathrm{H}-\mathrm{ZSM}-5$. In this respect, a large contribution of lower coordinated Co sites promotes methane formation through the direct hydrogenation of $\mathrm{CO}$ and hydrogenolysis and makes the catalyst sensitive to changes in $\mathrm{H}_{2}$ concentration in terms of selectivity toward $\mathrm{C} 1$.

\section{Experimental Section}

Amorphous $\mathrm{SiO}_{2}$ (CARiACT Q-10) with surface area and pore volume of $293 \mathrm{~m}^{2} \mathrm{~g}^{-1}$ and $1.35 \mathrm{~cm}^{3} \mathrm{~g}^{-1}$, respectively, was provided by Fuji Silysia Chemical Ltd (Japan). ZSM-5 zeolite in the ammonium form with a nominal $\mathrm{Si} / \mathrm{Al}$ ratio of 40 was purchased from Zeolyst (CBV 8014) and calcined at $823 \mathrm{~K}$ for $5 \mathrm{~h}$ to obtain H-ZSM-5. TPAOH (1 M), $\mathrm{HNO}_{3} \quad(70 \mathrm{wt} \%)$, ruthenium(III) nitrosyl nitrate (1.5 wt \%), and zirconyl nitrate (5 wt \%) solutions as well as the cobalt(II) nitrate hexahydrate salt were purchased from Sigma-Aldrich. All chemicals were used without any further purification.

Mesoporous H-ZSM-5 was prepared through base and acid treatments, as described earlier: $:^{[13 b]}$ In brief, desilication was performed in TPAOH aqueous solution (1 $\mathrm{m}$ ) placed in a capped vessel (volu$\mathrm{me}_{\text {base solution }} /$ weight $_{\text {zeolite }}=8.0 \mathrm{~cm}^{3} \mathrm{~g}^{-1}$ ) and at $343 \mathrm{~K}$ for $1 \mathrm{~h}$ under stirring in an oil bath. This treatment was followed by immediate quenching in an ice water bath and centrifugation to separate the zeolite powder from the solution. The residue of the desilicating agent was removed from the zeolite crystallites through subsequent redispersion in deionized water and centrifugation cycles until neutral $\mathrm{pH}$ was reached. The samples were then kept overnight at $333 \mathrm{~K}$ followed by drying at $393 \mathrm{~K}$ for $12 \mathrm{~h}$ and calcination at $823 \mathrm{~K}$ for $5 \mathrm{~h}$. After heat treatments, the mesoporous $\mathrm{H}-\mathrm{ZSM}-5$ samples were acid treated in aq $\mathrm{HNO}_{3}(1 \mathrm{M}$; volume acid solution/ weight $_{\text {zeolite }}=28.6 \mathrm{~cm}^{3} \mathrm{~g}^{-1}$ ) at $343 \mathrm{~K}$ for $2 \mathrm{~h}$ under stirring in an oil bath. After quenching, the samples were washed thoroughly with deionized water, dried, and calcined similarly as after the abovementioned desilication method. Mesoporous H-ZSM- 5 before acid treatment was labeled as mesoH-ZSM-5(o), and the acid-washed zeolite was labeled as mesoH-ZSM-5.

The catalysts for FTS were prepared through incipient wetness impregnation. All the supports were dried overnight at $393 \mathrm{~K}$ before impregnation. To study the promoting effect of $\mathrm{ZrO}_{2}$, a fraction of mesoH-ZSM-5 was loaded with $\mathrm{Zr}(\approx 5 \mathrm{wt} \%)$ by using a zirconyl nitrate solution. This sample was then kept overnight in a desiccator at RT, dried at $393 \mathrm{~K}$ for $12 \mathrm{~h}$, and calcined at $823 \mathrm{~K}$ for $5 \mathrm{~h}$; the resulting sample was labeled as $\mathrm{ZrO}_{2} /$ mesoH-ZSM-5. Amorphous $\mathrm{SiO}_{2}$, mesoH-ZSM-5(o), mesoH-ZSM- 5 , and $\mathrm{ZrO}_{2} /$ mesoH-ZSM-5 were used as carriers and loaded with Co $(\approx 20 \mathrm{wt} \%$ or $10 \mathrm{wt} \%$ in one case for each sample) by using aqueous cobalt(II) nitrate hexahydrate solutions as precursors. To investigate Ru as a catalyst promoter, ruthenium nitrosyl nitrate was added to the precursor solution and co-impregnated with Co to obtain a Ru loading of $0.3 \mathrm{wt} \%$. After impregnation, the samples were dried in a desiccator at $393 \mathrm{~K}$ as explained above. Then, the catalysts were calcined at $673 \mathrm{~K}$ for $2 \mathrm{~h}$. All the above-mentioned drying and calcination steps were performed at a heating rate of $2 \mathrm{Kmin}^{-1}$ and under static air conditions.

$\mathrm{N}_{2}$ physisorption was performed in an Autosorb 6B unit (Quantachrome Instruments) at liquid nitrogen temperature $(77 \mathrm{~K})$. Before the experiment, the samples $(\approx 0.1 \mathrm{~g})$ were degassed overnight in an Autosorb Degasser unit (Quantachrome Instruments) under vacuum at $623 \mathrm{~K}$.

Elemental analysis was performed with Perkin-Elmer Optima instruments. The samples were digested in an acid mixture. After dilution, analysis was performed by using inductively coupled plasma optical emission spectrometry (ICP-OES).

The XRD patterns were recorded in Bragg-Brentano geometry with a Bruker D8 Advance X-ray diffractometer equipped with a LynxEye position-sensitive detector. Measurements were performed at RT by using monochromatic $\operatorname{CoK}_{\alpha}(\lambda=1.788970 \AA)$ radiation at $2 \theta=5^{\circ}$ and $90^{\circ}$. All patterns were background subtracted to eliminate the contribution of air scatter and possible fluorescence radiation. 
$\mathrm{NH}_{3}$-TPD was measured with an AutoChem II chemisorption analyzer (Micromeritics). The zeolite-containing samples $(\approx 0.2 \mathrm{~g})$ were first degassed under He flow at $673 \mathrm{~K}$ for $1 \mathrm{~h}$ and then saturated with $\mathrm{NH}_{3}$ at $473 \mathrm{~K}$ during $1 \mathrm{~h}$ by using a flow of $1.65 \% \mathrm{NH}_{3}$ in $\mathrm{He}$. The gas mixture was then switched back to $\mathrm{He}$, and the sample was purged at $473 \mathrm{~K}$ for $1 \mathrm{~h}$ to remove the weakly adsorbed $\mathrm{NH}_{3}$ molecules until no $\mathrm{NH}_{3}$ was detected. Temperature-programmed desorption was subsequently recorded under He flow from 473 to $873 \mathrm{~K}$. All flow rates were adjusted to $25 \mathrm{~cm}_{\text {STP }}^{3} \min ^{-1}$ and the heating rates were $10 \mathrm{Kmin}^{-1}$ during different stages of the experiment.

The amount of Brønsted and Lewis acid sites in H-ZSM-5 and mesoH-ZSM- 5 were evaluated by using pyridine adsorption, which was performed with a Nicolet 6700 FT-IR spectrometer (Thermo Scientific) equipped with a MCT-B detector. A zeolite sample $(\approx 0.05 \mathrm{~g})$ was pressed at $1132 \mathrm{~kg} \mathrm{~cm}^{2}$ for $5 \mathrm{~s}$ to form a self-supporting wafer of $1.5 \mathrm{~cm}$ diameter. The sample was then degassed at $673 \mathrm{~K}$ for $2 \mathrm{~h}$ under vacuum $\left[2 \times 10^{-5} \mathrm{mbar}(1 \mathrm{bar}=100 \mathrm{kPa})\right]$. Pyridine vapor was added stepwise to the sample at a known volume and pressure. After each step, the sample was heated at $433 \mathrm{~K}$ to allow diffusion of the probe molecules and then cooled to RT for spectra collection. ${ }^{[35]}$ This method was repeated to estimate the extinction coefficient until no further increase was observed in the areas of adsorbed pyridine upon pyridine addition. Finally, the sample was heated at $433 \mathrm{~K}$ under vacuum and the final spectrum was recorded at RT. During each measurement, 128 scans were recorded in $1000-4000 \mathrm{~cm}^{-1}$ range at a resolution of $4 \mathrm{~cm}^{-1}$. The degassed sample was recorded as a background spectrum.

TEM was performed with an FEI Tecnai TF20 microscope using a carbon-coated $\mathrm{Cu}$ grid. Before analysis, the samples were reduced in an $\mathrm{H}_{2}$ flow of $80 \mathrm{~cm}_{\mathrm{STP}}^{3} \mathrm{~min}^{-1}$ at $773 \mathrm{~K}$ for $13 \mathrm{~h}$ (heating rate $=2 \mathrm{Kmin}^{-1}$ ) and transferred to the grid in a glove box. For the introduction of the samples into the microscope, a transfer unit was used to prevent any contact with air.

TPR- $\mathrm{H}_{2}$ was performed with a homemade equipment. The Co-containing samples $(\approx 0.1 \mathrm{~g})$ were subjected to a $7.4 \% \mathrm{H}_{2}$ flow of $27 \mathrm{~cm}_{\text {STP }}^{3} \min ^{-1}$ in $\mathrm{Ar}$ in a temperature-controlled reactor. The reactor temperature was ramped from RT to $1223 \mathrm{~K}$ (heating rate $=$ $5 \mathrm{Kmin}^{-1}$ ), and the $\mathrm{H}_{2}$ consumption was monitored with a thermal conductivity detector. Water was removed with a Perma Pure membrane dryer. Calibration was performed with CuO (Alfa Aesar), and total $\mathrm{H}_{2}$ consumption values were obtained from TPR- $\mathrm{H}_{2}$ patterns. The ratio between the $\mathrm{H}_{2}$ consumption and the corresponding theoretical value, calculated for the full reduction of each catalyst (assuming all $\mathrm{Co}$ atoms to be initially in the form of $\mathrm{CO}_{3} \mathrm{O}_{4}$ ), was reported as the degree of reduction.

XAS was performed at beamline X18A of National Synchrotron Light Source in Brookhaven National Laboratory (NY, USA). The beamline used the $\mathrm{Si}(111)$ channel-cut monochromator and provided an energy range of 5-25 keV. All the measurements were performed at RT in the transmittance mode. Incident and transmitted X-rays were detected with ion chambers. EXAFS and XANES data were collected on the $\mathrm{K}$ edge of Co. All Co-containing samples were measured against the Co foil used as a reference. In typical XAS experiments, the powder samples were placed into a $1.27 \mathrm{~cm}$ stainless steel washer and sealed from both sides with the Kapton tape. This configuration enabled us to keep the sample thickness constant. Air-sensitive samples (i.e., activated catalysts) were loaded into a dedicated cell. The cell consisted of an airtight stainless steel chamber equipped with two Kapton windows for the beam passing and a clamped cap for loading. The sample holder was located in the middle of this cell under $\mathrm{N}_{2}$ atmosphere in a glove box and sealed. The EXAFS data were processed by Athena (version 0.8.056). The background subtraction was performed by using the automated single-variable fit implemented in Athena. The Fourier transform of the reciprocal space data was performed by using the Hanning window in the $k$ range of $2-10 \AA^{-1}$

The acid-catalyzed reactions were performed in a fixed-bed stainless steel reactor with $n$-hexane and 1 -hexene as hydrocarbon model compounds. The fresh catalyst particles $(0.250 \mathrm{~g}, 100$ $212 \mu \mathrm{m}$ in size) were fixed in the reactor ( $3.9 \mathrm{~mm}$ inner diameter) between quartz wool plugs. The samples were treated overnight under $\mathrm{H}_{2}$ flow at $673 \mathrm{~K}$ and atmospheric pressure. After cooling the samples to $513 \mathrm{~K}$, the pressure was increased to $15 \mathrm{bar}$, and subsequently, a mixture of $\mathrm{C} 6, \mathrm{H}_{2}$, and $\mathrm{N}_{2}$ was fed to the reactor (space velocity $(\mathrm{SV})=13 \mathrm{~mol}_{\mathrm{C} 6} \mathrm{~kg}_{\mathrm{cat}}^{-1} \mathrm{~h}^{-1}, \mathrm{H}_{2} / \mathrm{C} 6=9.0$, and $\mathrm{N}_{2} / \mathrm{H}_{2}=$ 2.0). After $20 \mathrm{~h}$ on stream, the product was analyzed on-line at $363 \mathrm{~K}$ with a CompactGC (Interscience) equipped with a PoraBOND $\mathrm{Q}$ column $(10 \mathrm{~m} \times 0.32 \mathrm{~mm})$ and a flame ionization detector (FID) and using $\mathrm{He}$ as the carrier gas.

FTS experiments were performed on a six-flow fixed-bed microreactor setup, as described elsewhere. ${ }^{[11]}$ For all experiments, the fresh catalyst $(0.250 \mathrm{~g}, 100-212 \mu \mathrm{m}$ in size) was diluted with $\mathrm{SiC}$ of similar size to attain a constant bed volume of approximately $1.3 \mathrm{~cm}^{3}$. Catalysts were activated in situ before the FTS reaction by $\mathrm{H}_{2}$ at $773 \mathrm{~K}$ for $13 \mathrm{~h}$ at atmospheric pressure followed by cooling to $453 \mathrm{~K}$ under $\mathrm{H}_{2}$ flow. After increasing the pressure to the process value (15 bar), CO was gradually introduced into the feed stream at $453 \mathrm{~K}$ to reach its final concentration $\left(\mathrm{H}_{2} / \mathrm{CO}=1\right.$ or 2$)$ in $1 \mathrm{~h}$. Subsequently, the reactor was heated to the process temperature $(513 \mathrm{~K})$.

To regenerate the catalysts, $\mathrm{CO}$ was excluded from the feed and the operating pressure was decreased to atmospheric pressure under $\mathrm{H}_{2}$ flow. Upon increasing the reactor temperature to $773 \mathrm{~K}$, the samples were reactivated in situ (as described) and a second FTS experiment was started as per the above-mentioned method. All the above heating and cooling steps were performed at a heating rate of $2 \mathrm{Kmin}^{-1}$.

During FTS experiments, heavy hydrocarbons (waxes) were collected with gas/liquid separators at $448 \mathrm{~K}$ and the reaction pressure. After expanding the product flow to atmospheric pressure by using back pressure controllers, lighter hydrocarbons and water were collected in cold traps at approximately $278 \mathrm{~K}$. After separation from water, these liquid hydrocarbons as well as the waxes were weighted, dissolved in $\mathrm{CS}_{2}$, and analyzed offline with a simulated distillation (SIMDIS) gas chromatograph (Hewlett-Packard HP 5890, Series II) equipped with an FID and HP-1 column $(7.5 \mathrm{~m} \times$ $0.53 \mathrm{~mm}$; film thickness $=2.65 \mu \mathrm{m}$ ) and using $\mathrm{He}$ as carrier gas. During the analysis, the oven temperature was ramped from 35 to $350 \mathrm{~K}\left(\mathrm{ramp}\right.$ rate $\left.=14 \mathrm{~K} \mathrm{~min}^{-1}\right)$ and maintained at the final temperature for 5 min. $\mathrm{N}_{2}, \mathrm{CO}$, and $\mathrm{CO}_{2}$ as well as light hydrocarbons in the gas phase were analyzed on-line with a CompactGC (Interscience) equipped with three columns and detectors in parallel and using $\mathrm{He}$ as a carrier gas. In the first column (Carboxen-1010, $10 \mathrm{~m} \times$ $0.32 \mathrm{~mm}), \mathrm{N}_{2}, \mathrm{CO}, \mathrm{CH}_{4}$, and $\mathrm{CO}_{2}$ were separated at $333 \mathrm{~K}$ and analyzed with a thermal conductivity detector. In the second column $\left(\mathrm{Al}_{2} \mathrm{O}_{3} / \mathrm{KCl}, 10 \mathrm{~m} \times 0.32 \mathrm{~mm}\right)$ and detection with an FID, separation between all C1-C4 components was achieved at $434 \mathrm{~K}$. In the third column (RTx-1, $0.5 \mu \mathrm{m}, 15 \mathrm{~m} \times 0.32 \mathrm{~mm}$ ), C5-C10 hydrocarbons were separated at $353 \mathrm{~K}$ and analyzed with an FID. 


\section{Acknowledgements}

This research has been performed within the framework of the CatchBio program (project no. 053.70.005). We gratefully acknowledge the support of the Smart Mix Program of the Netherlands Ministry of Economic Affairs and the Netherlands Ministry of Education, Culture and Science. Dr. Patricia Kooyman is acknowledged for their assistance in TEM imaging. The use of the National Synchrotron Light Source, Brookhaven National Laboratory, was supported by the U.S. Department of Energy, Office of Science, Office of Basic Energy Sciences, under contract no. DEAC02-98CH10886. Dr. E. Stavitski and Dr. S.N. Ehrlich are gratefully acknowledged for their help during beamtime at beamline X18A of National Synchrotron Light Source. Dr. Adam Chojecki and Dr. Rob Edam are gratefully acknowledged for their assistance in $2 D G C$ analysis.

Keywords: alkenes - cobalt - Fischer-Tropsch synthesis mesoporous materials $\cdot$ zeolites

[1] D. A. Wood, C. Nwaoha, B. F. Towler, J. Nat. Gas Sci. Eng. 2012, 9, $196-$ 208.

[2] R. Guettel, U. Kunz, T. Turek, Chem. Eng. Technol. 2008, 31, 746-754.

[3] a) S. R. Deshmukh, A. L. Y. Tonkovich, J. S. McDaniel, L. D. Schrader, C. D. Burton, K. T. Jarosch, A. M. Simpson, D. R. Kilanowski, S. LeViness, Biofuels 2011, 2, 315-324; b) O. O. James, B. Chowdhury, M. A. Mesubi, S. Maity, RSC Adv. 2012, 2, 7347-7366.

[4] A. de Klerk, E. Furimsky, Catalysis in the Refining of Fischer-Tropsch Syncrude, RSCPublishing, Cambridge, UK, 2010.

[5] Q. Zhang, J. Kang, Y. Wang, ChemCatChem 2010, 2, 1030-1058.

[6] a) V. U. S. Rao, R. J. Gormley, A. Shamsi, T. R. Petrick, J. M. Stencel, R. R. Schehl, R. D. H. Chi, R. T. Obermyer, J. Mol. Catal. 1985, 29, 271-283; b) V. Udaya, S. Rao, R. J. Gormley, Catal. Today 1990, 6, 207-234.

[7] a) A. N. Pour, M. Zare, S. M. Kamali Shahri, Y. Zamani, M. R. Alaei, J. Nat. Gas Sci. Eng. 2009, 1, 183-189; b) A. Freitez, K. Pabst, B. Kraushaar-Czarnetzki, G. Schaub, Ind. Eng. Chem. Res. 2011, 50, 13732-13741.

[8] a) A. Martínez, J. Rollán, M. A. Arribas, H. S. Cerqueira, A. F. Costa, E. F. S. -Aguiar, J. Catal. 2007, 249, 162-173; b) A. Martínez, S. Valencia, R. Murciano, H. S. Cerqueira, A. F. Costa, E. F. S. -Aguiar, Appl. Catal. A 2008, 346, 117-125.

[9] G. Yang, C. Xing, W. Hirohama, Y. Jin, C. Zeng, Y. Suehiro, T. Wang, Y. Yoneyama, N. Tsubaki, Catal. Today, 2013, 215, 29-35.

[10] C. Kibby, K. Jothimurugesan, T. Das, H. S. Lacheen, T. Rea, R. J. Saxton, Catal. Today, in press, 2013, 215, 131-141.

[11] S. Sartipi, J. van Dijk, J. Gascon, F. Kapteijn, Appl. Catal. A 2013, 456, 11 22.

[12] a) J. Kang, K. Cheng, L. Zhang, Q. Zhang, J. Ding, W. Hua, Y. Lou, Q. Zhai, Y. Wang, Angew. Chem. 2011, 123, 5306-5309; Angew. Chem. Int. Ed. 2011, 50, 5200-5203; b) K. Cheng, J. Kang, S. Huang, Z. You, Q. Zhang J. Ding, W. Hua, Y. Lou, W. Deng, Y. Wang, ACS Catal. 2012, 2, 441-449.
[13] a) S. Sartipi, K. Parashar, M. Makkee, J. Gascon, F. Kapteijn, Catal. Sci. Technol. 2013, 3, 572-575; b) S. Sartipi, K. Parashar, M. J. Valero-Romero, V. P. Santos, B. Van Der Linden, M. Makkee, F. Kapteijn, J. Gascon, J. Catal. 2013, 305, 179-190.

[14] S. Sartipi, M. Alberts, M. J. Meijerink, T. C. Keller, J. Pérez-Ramírez, J. Gascon, F. Kapteijn, ChemSusChem 2013, 1646-1650.

[15] S. Abelló, A. Bonilla, J. Pérez-Ramírez, Appl. Catal. A 2009, 364, 191 198.

[16] D. Verboekend, G. Vilé, J. Pérez-Ramírez, Cryst. Growth Des. 2012, 12, $3123-3132$.

[17] S. Mitchell, N. L. Michels, K. Kunze, J. Pérez-Ramírez, Nat. Chem. 2012, 4, $825-831$.

[18] X. B. Li, X. Y. Jiang, Chem. Technol. Fuels Oils 2013, 49, 156-164.

[19] a) P. Arnoldy, J. A. Moulijn, J. Catal. 1985, 93, 38-54; b) S. Sartipi, A. A. Khodadadi, Y. Mortazavi, Appl. Catal. B 2008, 83, 214-220.

[20] F. Diehl, A. Y. Khodakov, Oil Gas Sci. Technol. 2009, 64, 11-24.

[21] A. Y. Khodakov, W. Chu, P. Fongarland, Chem. Rev. 2007, 107, $1692-$ 1744.

[22] a) R. B. Greegor, F. W. Lytle, R. L. Chin, D. M. Hercules, J. Phys. Chem. 1981, 85, 1232-1235; b) W. Chu, P. A. Chernavskii, L. Gengembre, G. A Pankina, P. Fongarland, A. Y. Khodakov, J. Catal. 2007, 252, 215-230; c) G. Jacobs, Y. Ji, B. H. Davis, D. Cronauer, A. J. Kropf, C. L. Marshall, Appl. Catal. A 2007, 333, 177-191.

[23] G. L. Bezemer, J. H. Bitter, H. P. C. E. Kuipers, H. Oosterbeek, J. E. Holewijn, X. Xu, F. Kapteijn, A. J. Van Diilen, K. P. De Jong, J. Am. Chem. Soc. 2006, 128, 3956-3964.

[24] C. Bouchy, G. Hastoy, E. Guillon, J. A. Martens, Oil Gas Sci. Technol. 2009, 64, $91-112$.

[25] M. Rigutto in Zeolites and Catalysis: Synthesis Reactions and Applications, Vol. 2 (Eds.: J. Čejka, A. Corma, S. Zones), Wiley-VCH, Weinheim, 2010, pp. $547-584$.

[26] W. Juszczyk, Z. Karpinski, J. Pielaszek, Z. Paal, J. Catal. 1993, 143, 583 593.

[27] a) N. E. Tsakoumis, M. Rønning, Ã. Borg, E. Rytter, A. Holmen, Catal. Today 2010, 154, 162-182; b) T. M. Eggenhuisen, P. Munnik, H. Talsma, P. E. De Jongh, K. P. De Jong, J. Catal. 2013, 297, 306-313.

[28] G. Prieto, J. Zečević, H. Friedrich, K. P. De Jong, P. E. De Jongh, Nat. Mater. 2013, 12, 34-39.

[29] a) E. Van Steen, M. Claeys, M. E. Dry, J. Van De Loosdrecht, E. L. Viljoen, J. L. Visagie, J. Phys. Chem. B 2005, 109, 3575-3577; b) J. van de Loosdrecht, B. Balzhinimaev, J. A. Dalmon, J. W. Niemantsverdriet, S. V. Tsybulya, A. M. Saib, P. J. van Berge, J. L. Visagie, Catal. Today 2007, 123, $293-$ 302.

[30] H. Schulz, Stud. Surf. Sci. Catal. 2007, 163, 177-199.

[31] J. P. Den Breejen, P. B. Radstake, G. L. Bezemer, J. H. Bitter, V. Frøseth, A. Holmen, K. P. De Jong, J. Am. Chem. Soc. 2009, 131, 7197-7203.

[32] R. Van Hardeveld, F. Hartog, Surf. Sci. 1969, 15, 189-230.

[33] H. J. Jung, S. S. Park, C. H. Shin, Y. K. Park, S. B. Hong, J. Catal. 2007, 245, $65-74$.

[34] R. J. Gormley, V. U. S. Rao, R. R. Anderson, R. R. Schehl, R. D. H. Chi, J. Catal. 1988, 113, 193-205.

[35] J. A. Z. Pieterse, S. Veefkind-Reyes, K. Seshan, L. Domokos, J. A. Lercher, J. Catal. 1999, 187, 518-520.

Received: July 30, 2013

Published online on October 23, 2013 